\title{
GLOBALIZAÇÃO E HISTÓRIA LOCAL
}

Jorge Antonio de Queiroz e Silva"

RESUMO:

Opresente artigo tem oobjetivo de analisar como oglobal interfere no local e como o ensino pode contribuir, por meio da história local participada por professores e alunos $\mathrm{com}$ a revitalização das linguagens e expressóes próprias de uma comunidade. UNITERMOS: Globalização, história local, memória.

\section{Globalização, neoliberalismo e fragmentação}

No início do século XXI, as ciências sociais são desafiadas com novos problemas. O indivíduo e a sociedade já não se localizam apenas nos limites de uma nação e de sua história. A cultura está repleta de idéias e imaginários surgidos de grupos, classes, etnias, minorias. A partir desta altura da história, a prohlemática das ciências sociais pode ter micro, macro e metainterpretações (IANNI, 1999).

A globalização econômica, que significa a destegulamentação ou supressão das regras que causam entraves aos lucros, vem influenciando todos os setores econômicos por meio da concorrência no plano mundial e do desenvolvimento do transporte e telecomunicações que suprimem os obstáculos à deslocalização de centros de produção (SIZE, 1997). Sob a lógica

" Graduado en História, cursando Especialização em Metodologia do Ensino de História, no Instituto Brasileiro de Pós-Craduação e Extensão (IBPEXX), Curitiba, PR. 
da dominação cultural, provoca-se a banalização das relações sociais e a fragmentação do indivíduo (MENEZES, 1996).

Conforme Menezes:

A segmentação da atividade do homem massacrado pelo processo de homogeneização, onde as pessoas pasteurizadas tornaram-se idênticas, presas ao universo do cotidiano, submissas ao consumo e à troca, capturadas pela mídia, encontram-se diante do cfềmero e do repetitivo como condição de reprodução (1996, p. 108).

Devido a crescente interconexão mundial das sociedades, diversos fenômenos sociais adquiriram escala verdadeiramente global [...]. A diferenciação em comunidades locais, tribos, clãs, grupos étnicos, naçôes e até mesmo Estados perdeu ao menos algo do seu significado anterior (SZTOMPKA upud IANNI, 1999, p. 170).

A ideologia do capitalismo na atual fase da globalização é o) neoliberalismo. Este propõe como políticas:

a) a razão de ser da economia não é o desenvolvimento (de todos (os aspectos), mas apenas o crescimento econômico;

b) o Estado é despojado do poder de garantir o mínimo de bens que todo o cidadão necessita e merece pelo fato de ser pessoa;

c) eliminam-se programas de oportunidades para todos, abrindoos apenas a grupos determinados;

d) privatizam-se empresas por se determinar que é melhor para todos;

e) as fronteiras são ahertas ao comércio e os pequenos produtores ficam sem proteção suficiente;

f) corta-se o investimento social com o objetivo de pagamento da dívida externa;

g) a gestão do dinheiro público é reduzida;

h) eliminam-se os obstáculos que as leis que protegem os trabalhadores poderiam causar; 
i) tira-se o encargo tributário e a obrigação com o meio ambiente dos grupos poderosos que são protegidos para que seja acelerada a industrialização (MOURA, 1997).

O neoliberalismo, que é a ideologia dominante, num período em que os EUA (Estados Unidos da América) detêm a hegemonia exclusiva do planeta, busca enfatizar os direitos do consumidor, não os do cidadão. "Defende um liberalismo moderno, restabelecendo a manutenção do livre jogo das forças econômicas e a iniciativa dos indivíduos, mas aceitando a limitação controlada do Estado" (LAROUSSE, 1998, p. 4183).

Nesse aguçamento do consumidor, deixando de lado os direitos do cidadão, a grande cidade fala a língua universal. Tudo se tornou universal e the permitiu fazer parte da globalidade. Mas esta cidade, ao se conectar à multiplicidade dos fatos, não se fará una. "Seguirá desfacelando-se, diminuindo, como se seus pedaços se desprendessem e criassem autonomia. Enfim, ao dar condiçôes à universalização, faz-se mais dividida" (GUATARI, 1985, p. 109-120).

A globalização e a fragmentação dão-se também no plano do indivíduo do mesmo modo que se dá no espaço. Na sociedade, essa fragmentação vem ocorrendo por meio da dissolução das relaçñes sociais que ligavam as pessoas à vida familiar e social como também sua relação com novos objetos (como a TV) que banalizam tudo: religião, política etc. O espaço mundializado se fragmenta por meio das formas de apropriação para o trabalho, o descanso, a moradia, o consumo.

Afirma Deleuze:

O espaço se fragmenta em espaços separados, parcelas fixas, como conseyuiência de uma atividade parcelada fundada no trabalho abstrato. O espaço aparece como mercadoria, apesar 
de suas especificidades, produzido e vendido enquanto solo urbano, cujo contéudo escapa aos indivíduos, posto que submissos à troca è à especulação [...]. Com isto transforma-se, constantemente, o lugar e produz-se o estranhamento do lugar com a perda das referências (1)ELEUZE, 1988, p. 16).

Por ser mundial, o processo urbano produz-se de modo desigual. Especificidades referentes a tempos e lugares são fundamentais para seu entendimento. Como conseqüencia, a reprodução da vida nem sempre traz condições de subsistência, por inexistência de rede de água, esgoto, asfalto, escolas, hospitais, etc. Em outras palavras, essa situação, que é fruto da contradição entre a produção socializada do espaço e sua apropriação privada, é a forma mais evidente

da vitória do valur de uso sobre o valor de troca e que [...] esclarece a naturezáa do processo de fragmentação do espaço. Essa vitória expressase também através das formas de dominação que se estabelecem em todos os níveis de vida (SANTOS, 1997, p. 195).

Os indivíduos se movimentam em todos os sentidos, mudam de paús, trocam o local pelo global e se diversificam. Dá-se o universalismo, cujo significadoé a relativização da própria forma de existência, atendendo-se às pretensões legítimas das demais formas de vida (IANNI apud SANTOS, 1997). O tempo eletrônico vai tecendo a vida de todo o mundo. Como o espaço, () tempo é uma mercadoria provida pelo computador, um material para ser moldado aos fins humanos. Enquanto um relógio transforma segundos em minutos e em horas idênticas, o computador transforma segundos, microssegundos em informação. O tempo é produto da atividade humana, uma invenção cultural.

No âmbito do mundo está o mercado. O mundo se torna 
fáhrica do engano, pois a dimensão mundial são as organizações internacionais, as universidades mundiais, as instituições supranacionais, as igrejas dissolventes. "Quando o Mundo assim feito está em toda parte, o embate ancestral entre a necessidade e a liberdade dá-se pela luta entre uma organização coercitiva e o exercício da espontaneidade. O resultado é a fragmentação" (SANTOS, 1997, p. 19).

A mundialização dos mercados possui alguns componentes específicos que a caracterizam: o primeiro deles é o impacto da revolução na informática e nas comunicações, passando pelas redes instantâneas de informação que, rapidamente, rastreiam a rentabilidade pelos cuatro cantos do mundo, ou seja, conforme Ramonet: o mercado financeiro reúne a imaterialidade, o imediatismo, o permanente e o planetário. "O milagre das comunicações desenvolve uma divinização dos procedimentos e dos comportamentos, constituindo um ritual sofisticado do culto ao mercado" (RAMONET, 1995, p. 193).

O mercado, portanto, tornou-se religião, mas poucos especialistas têm acesso a ela. Apenas aqueles que conhecem os ritos para obter maiores lucros, pois têm o poder de provocar altas e baixas no dólar, na bolsa de preços agrícolas tanto em Nova Iorque, como em Tóquio ou Londres. Eles guardam seus capitais nos paraísos fiscais, sem o controle dos Estados, dos governos, pois estão acima, ou à margem, de sanções ou leis fiscais e institucionais, já que é o capital financeiro que estabelece suas próprias fronteiras (AZEVEDO, 2000).

Para Menezes (1986), a cidade vem se consolidando como a base físico-espacial do fenômeno da globalização: Cada vez mais elas são inseridas em sistemas econômico-financeiros e de comunicação de alta complexidade" e, como afirma Giddens (apud MENEZES, 1996, p. 145): 
quem quer que estude as cidades hoje em dia, em qualquer parte do mundo, está ciente de que o que ocorre numa vizinhança local tende a ser influenciado por fatores - tais como dinheiro mundial e mercado de bens - operando a uma distância indefinida da vizinhança em questão.

Hoje o que é federativo ao nível mundial não é uma vontade de liberdade, mas de dominação, não é o desejo de cooperação mas de competição, tudo isso exigindo um rígido esquema de organização yue atravessa os rincões da vida humana. Com tais desígnios, o que globaliza falsifica, corrompe, desequilibra, destrói. E ainda: [...] lugar torna-se o mundo do veraz e da esperança e o global, mediatizado por uma organização perversa, o lugar da falsidade e do engrodo [...]. Olocal permite a união [...]. É pelo lugar que revemoso mundo e ajustamos nossa interpretação, pois nele o recôndito, o permanente, o real triunfam, afinal, sobre o movimento, o passageiro, o imposto de fora (SANTOS, 1997, p. 196).

"É como se a história começasse novamente [...]. A sociedade global envolve outros e novos modos de ser, viver, trabalhar, agir, sentir, pensar, sonhar, imaginar. Trata-se de um horizonte histórico e teórico no qual o indivíduo, grupo, etnia, minoria, classe, sociedade, povo, democracia, história, [...] adquirem novos significados" (IANNI, 1997, p. 177), colocando a pesquisa a serviço dos humanos.

Não se trata [...] de inibir a pesquisa e frear os avanços, mas de pô-los a serviço dos seres humanos, [pois] o desemprego no mundo nãoé uma fatalidade. É antes o resultado de uma globalização da economia e de avanços tecnológicos a yue vem faltando o dever ser de uma ética realmente a serviço do ser humano e não do hucroe da guldedice irrefreada das minorias que comandam o mundo (FREIRE, 1997, p. 249. 250). 
As populações adquirem outro sentido na medida em que, pensando em sua individualidade e globalidade, podem desenvolver um modo diferente de imaginação, uma nova autoconsciência. "No âmbito da sociedade global, tanto se rompem singularidades e universalidades herdadas de forma pretéritas, como emergem novas, constitutivas de outras formas de ser e pensar. A dialética singular e universal não só se modifica como pode modificar-se substancialmente, revelando mediações recriadas, novas, insuspeitadas" (IANNI, 1997, p. 180), deixando de lado os discursos anestesiantes.

O professor, o membro de uma comunidade que tem seus próprios caminhos, precisa estar advertido do poder do discurso ideológico que anestesia a mente, confunde a curiosidade e distorce a percepção dos fatos, dos acontecimentos. Não se pode escutar, por exemplo, discurso como estes, sem reagir: o desemprego no mundo é uma fatalidade do fim do século, pois isto é autoritarismo e "o caminho autoritário já é em si uma contravenção à natureza inquietamente indagadora, buscadora, de homens e de mulheres que se perdem, perdem a liberdade" (FREIRE, 1997).

Nessa altura da história, "O singular e o universal tanto se impregnam de outras novas mediações como encontram outras e novas possibilidades de se expressar, realizar, desenvolver, florescer" (IANNI, 1997, p. 182).

Como afirma Ortiz (1997, p. 273): "[...] a mundialização da cultura, para existir, deve se tornar uma dimensão da vida cotidiana, deve-se localizar. Porém, assim o fazendo, ela rearticula as relações de força dos lugares nos quais se enraíza”.

O historiador trabalha de maneira a responder às inquietações - que ele reparte - de seus contemporâneos (ARIÈS, 1989), e que, em geral, o ensino de História vem provocando o desinteresse dos alunos, excluindo a possibilidade 
de compreensão da globalidade e do real, ao se propor um conjunto de fatos históricos sem que eles possam compreender o real significado das coisas (SCHIMIDT, 2000). A sua inserção na historia local torna-se importante saber escolar a ser incorporado pelas novas propostas curriculares devido à sua importância para a "compreensão da contemporaneidade" (SCHIMII)T, 2000, p. 207) e por buscar a reconstituição de fatos e vidas.

\section{Globalização e história local}

Diante da complexidade da globalização, os historiadores deparam-se com a necessidade de dilatar seus horizontes teóricos, pois as sociedades atuais e os diferentes sistemas mundiais mudam velozmente. Segundo Avelino (1997), "a crescente miserabilidade de uma parte significativa da população mundial, as desigualdades sociais cule se acentuam em todos os países, hem como as grandes devastações ambientais, levam-nos enquanto historiadores e cidadãos, a pensar que, verdadeiramente, o que está em crise é o modelo de civilização adotado".

Ariès (1989, p. 230), afirma:

À medida que crescem as divisões entre os pobres, também a globalização provoca movimentos mais evidentes dos seres humanos yue cruzam as linhas divisórias, entre regióes e classificaçōes. Parece que vivemos num universo com uma fonte de problemas não resolvidos. Só a História pode responder a este espanto e reduzir, ou, pelo menos, limitar e precisar o absurdo do mundo, na medida em que responde aos problemas levantados pelo presente.

Uma das características da globalização, segundo Ianni 
(1997) é a perda das referências, é a destruição do passado. Para Hobshawn (1995) esta destruição foi um dos fenômenos mais tristes do final do século XX. O crescimento dos jovens vem ocorrendo numa forma de presente constante, sem relação) alguma orgânica com o passado público da época em que vivem. Então os historiadores, com a missão de lembrar o que é esquecido, tornam-se muito importantes, especialmente na preservação da memória e resgate da história local.

Um dos modos interessantes de resistir aos efeitos negativos da globalização, sendo um deles a efemeridade das verdades, é a vivência, segundo Levy (1993), das três tecnologias: a oralidade, que resguarda a memória; a escrita/ impressão, que mantém o caráter de devir (história) e a informática/rede, que ensina relações com múltiplos centros, como uma teia. As três grandes tecnologias devem estar presentes na sala de aula, pois elas devem ser entendidas como modos de fazer.

Convivem num mesmo local a latência das histórias guardadas nas memórias dos indivíduos, que talvez tenham sido reveladas e que correm o risco de perder-se para sempre, e a velocidade do hipertexto, que estabelece informação e interação o tempo todo. Sem o resgate das identidades locais, os indivíduos sentem-se desconhecidos, sem raízes, pois a interação nas redes de informação, como um contexto partilhado, perde seu significado sem a dialética da relação presente-passado. Quanto mais cresce a velocidade da interação do hipertexto, portanto, mais surge a necessidade de valorizar a oralidade e a escrita.

A preservação da memória local é um dos modos mais inteligentes e duradouros de resistir, como afirma Bosi (1994, p. 452):

Podem arrasar as casas, mudar o curso das ruas; as pedras podem mudar de lugar, mas como destruir os vínculos com que os homens 
se ligavam a elas? [...] À resistência muda das coisas, à teimosia das pedras, une-se a reheldia da memória cue as repõe em seu lugar antigo.

Se a resistência aos efeitos negativos da globalização e das fragmentações por ela instituída conduz à preservação da memória, constrói uma consciência histórica yue, segundo Menezes (1984, p. 33) passa a ser vista como força viva do presente como referência da mudança, pois "se não houver memória, a mudança será sempre fator de alienação e desagregação", ou seja, mantendo a consciência histórica, pode-se tirar vantagens inclusive daquilo que possa não ser positivo no processo de globalização.

\subsection{Esboços da história local}

Segundo Goubert (1988) o local significa a referência dada à caminhada de um dia, em média 10 a 15 quilômetros. Nesse âmbito existem idéias, leis e práticas culturais comuns e crenças religiosas similares. Todos se sentem cidadãos ali.

Para Ossana, citada por Schmidt (2000, p. 214):

O trabalho com a História local no ensino de História pode ser um instrumento idôneo para a construção de uma história mais plural, menos homogênea, que não silencie as especificidades. O local ou o regional, institúdos como objetos de estudo, podem ser contrastados com outros âmbitos e indicar a pluralidade em dois sentidos: na possibilidade de se ver mais de uma história ou mais de um eixo na própria história do lugar ou na possibilidade de ser outras histórias micro, partes, todas elas, de alguma outra história que as englobe e, ao mesmo tempo, que reconheça suats particularidades.

Embora haja poucos escritos sobre história local no Brasil, e ela seja atualmente "um mero rabisco para acender a imaginação do historiador" (SAMUEL, 1990, p. 1), é possível 
esboçar, pouco a pouco, alguns dos seus aspectos: a História local permite um conceito mais imediato do passado; possui a força de ser popular nas atividades e na forma literária enquanto trazem informações do cotidiano por seus jornais, pela rádio municipal, por meio de panfletos, entre outros, que revelam a força do dia-a-dia daquela comunidade. No convívio, as pessoas referem-se a locais onde moram, o modo de viverem dos antepassados e a valorização da iconografia por meio de velhos contratos, cartas de namoro e cartões postais (SAMUEL, 1990).

\subsubsection{As formas surdas de resistência}

Ao objeto escolhido pelo historiador cabe dar uma explicação global dos fatos humanos. O que deve ser proposto não é um estudo paralelo do social, do cultural, do econômico, do político, mas um estudo que não compartimentalize, nem subordine. Tanto à história local quanto à social,

[...] interessam ao investigador as lutas reais; não só aqueles que se expressam sob formas organizadas (sindicatos, partidos, associações várias) como também as "formas surdas" de resistência, estratégias ocultas de subordinação e controle. Isto significa incorporar grandes áreas da experiência humana sem as quais a compreensão do social se torna precária. Interessa recuperar caminhadas, programas fracassados, derrotas utopias, pois nada nos garante que o que ganhou foi sempre melhor (FENELON apud VIEIRA et al., 1998, p. 18).

A este propósito Jetté (1996) afirma que através da História o indivíduo tem a possibilidade de se distanciar do presente para distinguir o que depende do hábito e o que depende da tradição, dos preconceitos e dos valores reais. Nessa ótica, a História local possui função moral no sentido de que todo conhecimento leva a agir. 
Atualmente a história leva em conta toda a experiência humana. Segundo Thompson (apud VIEIRA et al., 1998, p. 17 18):

Pensar a história como toda experiência humana entendida sempre como experiência de classe que é de luta, e valorizar a natureza política dessa luta, significa considerar então que a história real é construída por homens reais, vivendo relações de dominação e subordinação em todas as dimensões do social, daí resultando processo de dominação e resistência. A partir daí, pensar a produção do conhecimento histórico não como aquele que tem implicaçôes apenas com o saber erudito, com a escolha do método, como desenvolvimento de técnicas, mas como aquele que é capaz de aprender e incorporar essa experiência vivida, é fazer retornar homens e mulheres não como sujeitos passivos e individualizados, mas como pessoas que vivem situações e relações sociais determinadas, com necessidades e interesses e com antagonismos. Traduzem essa experiência na sua consciência como cultura - valores, tradições, idéias, instituições, arte, religião etc.

Os estudos locais tornam-se material valioso, especialmente para a percepção dos costumes, das idéias da mentalidade de uma determinada época de sua reprodução, pois retratam os acontecimentos de sua época e os valoriza.

\subsubsection{Linguagens}

No fato da história valorizar as diferentes linguagens está a idéia de que relações de dominação e subordinação se atualizam em todas as formas de vida social. "Nesta linha de raciocínio, uma questão que se coloca para o historiador é observar quem 
produz uma dada linguagem, para quem produz, como a produz e quem a domina" (VIEIRA et al., 1998, p. 20).

É preciso ter presente que a linguagem por si não recupera a realidade, ela apenas traz para a mente do historiador associação de imagens. Numa foto, por exemplo, o historiador precisa alcançar não apenas o que foi fotografado, mas também o fotógrafo, tendo atenção "ao modo como a linguagem foi produzida tentando responder por que as coisas estão representadas de uma determinada maneira, antes de se perguntar o que está representando" (VIEIRA et al., 1998, p. 23).

O importante é o diálogo que o historiador realiza com as evidências através de suas reflexões ou das reflexões feitas por outras disciplinas. Depende também da cultura histórica do pesquisador o saber perguntar, sendo que as perguntas dependem do conhecimento externo do pesquisador. Para Cardoso as fontes só saberão falar se o historiador souber fazer as perguntas, pois a "história é uma ciência em construção" (1981, p. 47).

\subsubsection{Arquivos locais e documentos}

Segundo Febre (apud REIS, 2000, p. 77):

o historiador não pode se resignar diante de lacunas na informação e deve procurar preenchê-las. Para isto, usará os documentos não só de arquivos, mas também um poema, um quadro, um drama, estatísticas, materiais arqueológicos. O historiador tem como tarefa vencer () esquecimento, preencher os silêncios, recuperar as palavras.

Para Rodrigues (1982) possui a máxima importância a preservação da documentação local e regional, pois a História Local contribui para a Historiografia e para às Ciências Sociais, embora sujeita ao perigo da fragmentação. É ali que estão os fatos do cotidiano do homem comum coletados nos arquivos das famílias ou das instituições e na memória dos idosos. 
Segundo Arruda (1999, p. 563)

a memória não vive se o seu suporte material for destruído, se sua forma concreta de ser evocada no presente, não mais existir. Se os objetos que nos ligam ao passado e articulam a nossa permanência no mundo, como continuadores de uma tradição, desaparecen ou se tornam objetos de simples consumo, a própria cultura também desapiarecerát.

Os arquivos locais e escolares possuem importância fundamental por oferecerem múltiplas possibilidades de utilização, inclusive o seu uso pedagógico, ainda pouco utilizado no Brasil. Diante da variedade de material, o historiador, pesquisador, professor deve adotar uma postura não rígida diante dos registros e uma visão não mecânica da documentação. Para que isso aconteça é importante que, além de conhecer técnicas de pesquisa, compreenda os materiais específicos que quer analisar. Tudo o que deriva do trabalho humano pode tornar-se vestígio ou fonte documental, mas é preciso saber selecionar e tratar adequadamente os documentos conforme a peculiariedade de suas características (SAMUEL, 1990).

Como os livros, manuscritos e tesouros de museus, também os arquivos públicos são fonte de cultura, tão importantes como parques, monumentos ou edifícios (SCHELLNEBERG, 1974). "A memória é filha do presente. Mas como seu objeto é a mudança, se lhe faltar o referencial do passado, o presente permanece incompreensível e o futuro escapa a qualquer projeto" (MENEZES, 1992, p. 14). A compreensão da memória "não depende somente do que se preservou mas também do desvendamento do significado do que se esqueceu. Não é suficiente dar voz aos excluídos, devese também huscar compreender as significações do silêncio e do esquecimento. Da mesma forma, deve-se procurar o significado das lacunas e ausências de fundo documental" (MENEZES, 1992). 
Por outro lado, o desenvolvimento urbano, a mercantilização, as indústrias culturais e o turismo não devem ser vistos como ameaças aos atuais processos de mudanças quanto à preservação do patrimônio histórico (LUPORINI, 1999), pois devem ser vistos como contextos onde esse patrimônio se insere. As linguagens como rádio, televisão, cinema, vídeos e discos convertem-se em meios para o registro e a divulgação cultural da própria comunidade que os criou integrando o patrimônio, embora de modo diferente dos outros bens culturais (CANCLINI, 1994).

\subsubsection{O aluno participa do processo histórico}

Através do ensino de História o aluno deve sentir-se participante do processo histórico, pois sua história individual é fruto de um processo e que ele também faz a história. Por isso, além de ele registrar sua própria história e do seu grupo familiar, pode intervir em sua realidade presente. Deste modo, conforme Citron (1990) um modo de rejeitar a rubrica que atesta a origem oficial da memória nacional como única memória coletiva é por meio do registro da pluralidade de memórias sociais, culturais e populares. E mais, a utilização de fontes orais, possibilita a escrita de outro tipo de história mais completo (GARRIDO, 1993). Sem a participação histórica do aluno ele sempre irá considerar que a história são os outros, mas ao inserir-se, sente-se seu construtor:

Uma história que projeta os destinos da sociedade, decididos por poucos homens, onde os acontecimentos cotidianos são apagados, onde a participação da população é, no máximo pano de fundo, resultando na construção da idéia de que a história são os outros [...]. Afinal, acabamos nos inserindo e participando de um imaginário onde a história se constrói ao nosso largo" (MONTENEGRO, 1991, p. 11). 
É importante que, por meio da participação do fazer histórico, o aluno compreenda como age o historiador e como produz o conhecimento, lembrando que seu trabalho é condicionado pelo nível de conhecimento existente e pelos interesses que defende, mesmo que inconscientemente (BORGES, 1986). Que se considere que a História é uma forma de conhecimento entre muitas outras em que se busca uma explicação para algo desconhecido por meio da procura do estabelecimento dos fatos e de sua interpretação e que escrever história é apenas a redução do campo das incertezas, não é o estabelecimento de certezas (BORGES, 1986), sem cair no extremo de relativizar a História.

O professor deve lembrar que o que ensina nas salas de aula não é o único modo que existe na sociedade de se pensar o passado, e que, em grande medida, o que se ensina vai tornandose aos poucos parte da memória; que por sua vez, transforma-se em objeto dos estudos historiográficos, e que, na tentativa de tematizar estas representações como construção de novas formas de pensar o passado e contribui-se na construção de uma sociedade mais democrática (ARRUL)A, 1999).

Se a globalização vem causando efeitos negativos, como enfatizado anteriormente, um dos seus aspectos positivos é, sem dúvida, a evolução das tecnologias da informática que de certa maneira favorece a interação. Construir a história local por meio da interação professor-alunos-local que constituem um novo modo de fazer a história, pois essa ação interativa por si só é um processo histórico de preservação da história dos alunos, de suas famílias e de seu contexto.

O aluno não precisa antes aprender na sala de aula e depois fazer a história, mas aprende enquanto participa como sujeito que considera os outros também como sujeitos ativos. Nessa ótica, concretiza-se a nova realidade que conjuga global-local, 
denominada como glocal (RUIGROK e VAN TULDER apud DREIFUSS, 1997), originando a conhecida frase: pense globalmente, atue localmente.

Essa ação deve animar especialmente os trabalhos educacionais do ensino de história, valoriza as expressóes de todas as linguagens, aonde revitalizam-se as etnias e as particularidades, num conhecimento sempre em construção. Professores e alunos aprendem sempre mais a revalorizar a alteridade do outro como parte da construção de sua própria identidade. Ao invés de sentiremse apreensivos diante do global, fortalecerão as expressões da história local.

\section{Agradecimentos}

- Todos os professores responsáveis, pela minha graduação em História, realizada pela FAFIMAN-Mandaguari.

- Mestra Cleusa Maria Fuckner, responsável pela orientação de minha monografia.

- Doutoranda Marlene Rosa Cainelli, que me orientou para a publicação deste artigo.

- Doutoranda Sônia Maria Chaves Haracemiv, que muito me impulsionou para os estudos da Pós-Graduação.

- Meus pais já falecidos (Gentil e Geny), que foram constantes em minha vida, apoiando-me na prática do conhecimento.

- Minha esposa Zélia, fonte de inspiração deste artigo. 


\section{Referências Bibliográficas}

ARIÉS, P. O tempo da história. Rio de Janeiro: Francisco Alves, 1989.

ARRUDA, G. História e memória: produção de cartazes didáticos. In: SCHMII)T, M. A.; CAINELLI, M. R. (Org.). III Econtro: Pespectivas do Ensino de História. Curitilar : Aos Quatro Ventros, 1999.

AVELINO, Y. 1). História c globalização. In: DOWBOR, L.; IANNI, P.; RESENIDE, P.-E. A. Desufios da globulizaçāo Petrópolis, R.J.: Vozes, 1997.

AZEVEDO, J. C. de. Escola cidadã, mercoescola e a reconversão cultural. In: FERREIRA, M. O. V.; GUGLIANO, A. A. Fragmentos da globalizuçūon na échucuçüo. Porto Alegre: Artes Médicas Sul, 2000.

BORGES, V. P. O quéc históriu. São Paulo: Brasiliense, 1986.

BOSI, E. Menúricue sociedude: lembranças de velhos. 3. ed. São Paulo: Cia. Das Letras, 1994.

CANCLINI, N. (i. O patrimônio cultural e a construção imaginária do social. Revista do Património Histórico Nacional. Brasília, n. 23, p. 95-1 11, 1994.

CARDOSO, C. F. Uma introdhçuão ù história. São Paulo: Brasiliense, 1981.

CITRON, S. Ensinar história hoje. A memória perdida reencontrada. Lisboa: Livros Horizonte, 1990.

DELEUZE, G. Diferençue repetição. São Paulo: GRAAL, 1988, p.16.

DREIFUSS, R. A. Comporaçōes estratégicas e mundialização da Cultura. São Paulo: Letra Lire, 1997.

FREIRE, P. (ilobalização ética e solidariedade. In: DOWBOR, L.; IANNI, P.; RESENDE, P.-E. A. Desufios da globalizaçũo. Petrópolis, R.J.: Vozes, 1997.

GARRIDO, J. del A. As fontes orais na pesuuisa histórica: uma contribuição ao debate. Revista Brasileira de História. Memória, história, historiografia. Dossiê ensino de história. São) Paulo: Marco Zero/Fapesp/Anpul/CNPy, set. 1992/ago. 1993.

GOUBERT, Pierre. História local. Revista Arrabaldes. Petrópolis, n. 1, 1988. 
GUATARI, F. Espaço e poder. a criação de territórios na cidade. São Paulo: NERU, n. 16, p. 109-120, 1985.

HOBSBAWN, E. Era dos extremos: o breve século XX (1914-1991). São Paulo: Companhia das Letras, 1995.

IANNI, (). A era do glohulismo. 3. ed. Rio de Janeiro: Civilização Brasileira, $1(x) 7$.

1999.

- A sociedade global. 8. ed. Rio de Janeiro: Civilização Brasileira,

JETTÉ, R. para uma concepção funcional de história. In: A HISTÓRIA e seu ensino. Coimbra: Almodina, 1996.

LAROUSSECULTURAL. Grande Enciclopédia. São Paulo: Plural, 1998, v. 21, p. 4183.

LEVY, P. As tecnologias da inteligência: o futuro do pensamento na era da informática. Rio de Janeiro: Edições 34, 1993.

LUPORINI, T. J. Os "lugares da memória" enquanto objeto da educação histórica. In: SCHMIDT, M. A.; CAINELLI, M. R. (Org.). III Encontro: Pespectivas do Ensino de História. Curitiba: Aos Quatro Ventros, 1999.

MENEZES, L. C. Desenvolimento urbano e meio ambiente: a experiência de Curitiba. Campinas, SP: Papirus, 1996.

MENEZES, U. P. Identidade cultural e arqueologia. In: Revista de Patrimônio Histórico e Artístico Nacional, n. 20, p. 33-36, 1984.

- A história cativa da memória? Para um mapeamento da memória no mundo das ciências. Revista do Instituto de Estudos Brasileiros. São Paulo, n. 34, p. 9-24, 1992.

MONTENEGRO, A. T. Lembranças de aluno mal comportado. Tópicos Educacioncis, Recife, v. 9, n. 1/2, p. 11-16, 1991.

MOURA, R. O futuro das megacidades - carta de São Paulo: Seminário Internacional realizado em São Paulo em 30 e 31 de outubro de 1995. Rev: Adm. Murn., Rio de Janciro, v. 44, n. 221, p. 8 -15, abr./dez. 1998.

ORTIZ, R. Mundialização, cultura e política. In: LADISLAU, D.; IANNI, O.; EDGAR, P.; RESENDE, P.-E. A. Desafios da globalização. Petrópolis, RJ: Vozes, 1997.

História \& Ensino, Londrinat, v. 7, p. 83-102, out. 2001 
RAMONET, I. Os novos rumos do mundo. Le monde, 9 fev. 1995. Apud Em Tempo, Porto Alegre, n. 283, ago. 1995, p. 22

REIS, J. C. Escolu dos Annules: a inovação em história. São Paulo: Paze Terra, 2000.

RODRIGUES, J. H. A pesquisa histórica no Brasil. São Paulo : Nacional, 1982.

SAMUEL, R. História local e história oral. Revista brasileira de História, v. 9, n. 19 , set. $89 /$ tev. 90.

SANTOS, M. A aceleração contemporânea: tempo mundo e espaço-mundo. In: IOOWBOR, L.; IANNI, P.; RESENDE, P.-E. A. Desafios da globalização) Petrópolis, R.J.: Vozes, 1997.

SCHELLEMBEG, T. R. Arquivos modemos. Rio de Janeiro: FGV, 1974.

SCHMILT, M. A. Construindo a relação conteúdo método no Ensino de História no Ensino Médio. In: KUENZER, A. Ensino médio: construindo uma proposta para os que vivem do traballho. São Paulo: Cortez, 2000.

SIZE, Pierre. Dicionário da globulizaçäo: a economia de "A" a "Z". Florianópolis: Obra jurídica, 1997, p. 56.

VIEIRA, M. do P. de A.; PEIXOTO, M. do R. da C.; KHOURY, Y.M. A. A pesquisa em história. 4. ed. São Paulo: Ática, 1998.

\section{ABSTRACT:}

This article intents to analyze how does the global influence on the local and how could the teaching contribute by means of the local history participated by both teachers and students with the revitalization of the languages and expressions concerning to a specific community.

KEY WORISS: Globalization; local history; memory. 